\title{
Gaussian Basis Sets for the Calculation of Some States of the Lanthanides
}

\author{
P.R. Librelon and F.E. Jorge* \\ Departamento de Fúsica \\ Universidade Federal do Espirito Santo \\ 29060-900 Vitória, ES, Brasil
}

Received on 19 October, 2000

\begin{abstract}
Highly accurate adapted Gaussian basis sets are used to study the ground and some excited states for the neutral atoms and also some corresponding 6 s and $4 \mathrm{f}$ ionized states from Cs through Lu. Our total energies are compared with those calculated with a numerical Hartree-Fock method. The mean error of our energy results is equal to 0.74 mhartree. Our calculations reproduce the experimental trend to increase or to decrease the $6 \mathrm{~s}$ and $4 \mathrm{f}$ ionization potentials with increasing atomic number, although they are respectively smaller and larger than the experimental values.
\end{abstract}

\section{Introduction}

In this last decade lanthanide chemistry and physics have experienced tremendous growth, for example in the field of catalysts [1] and high temperature superconductors [2]. Thus, it would be highly desirable to elucidate the electronic structure of lanthanide atoms at least in the Hartree-Fock (HF) approximation. For these atoms, numerical HF (NHF) calculations [3-5] were performed mainly on the ground states.

In this work, the adapted Gaussian basis sets [AGBSs - one different set of Gaussian-type function (GTF) exponents for each atomic species for the atoms from Cs $(\mathrm{Z}=55)$ through $\mathrm{Lu}(\mathrm{Z}=71)$ [6] are initially augmented until saturation is achieved for each symmetry of each atom and then, using the generator coordinate $\mathrm{HF}$ (GCHF) [7] method, they are reoptimized for each atomic species. Next the energies for the atoms $\mathrm{Cs}-\mathrm{Lu}$ and their positive ions are calculated and compared with those obtained with a NHF [5] method. The ionization potentials (IPs) are also computed and compared with the corresponding experimental values $[8,9]$.

\section{The method}

An approach to select the basis sets arises from the GCHF method [7]. In the GCHF method the oneelectron functions are integral transforms, i.e.,

$$
\Psi_{1}(1)=\int \phi_{i}(1, \alpha) f_{i}(\alpha) d \alpha \quad i=1, \ldots, n,
$$

where $\phi_{i}$ are the generator functions (GTFs in our case), $f_{i}$ are the unknown weight functions, and $\alpha$ is the generator coordinate. The application of the variational principle to calculate the energy expectation value built with such one-electron functions leads to the Grifftn-Hill-Wheeler-HF (GHWHF) equations [7]. The GHWHF equations are integrated using a procedure known as integral discretization (ID) [10]. The ID technique is implemented through a relabelling of the generator coordinate space, i.e.,

$$
\Omega=\ln \frac{\alpha}{A}, A>1
$$

where $A$ is a numerically determined scaling factor. In the new generator coordinate space $\Omega$, an equally spaced $N$-point mesh $\left\{\Omega_{i}\right\}$ is selected, and the integration range is characterized by a starting point $\Omega_{\min }$, an increment $\Delta \Omega$, and $N$ (number of discretization points). The highest value $\left(\Omega_{\max }\right)$ for the generator coordinate is given by

$$
\Omega_{\max }=\Omega_{\min }+(N-1) \Delta \Omega .
$$

The choice of the discretization points determines the exponents of the GTFs.

In the last four years, the GCHF [7] method was successfully tested in the generation of basis sets for atomic and molecular systems [11-16].

\footnotetext{
*e-mail: jorge@cce.ufes.br
} 


\section{III Results and discussion}

By employing the GCHF method we have generated AGBSs for the atomic species presented in Table 1. Throughout the calculations we have used the scaling factor $A$ (see Eq. (2)) equal to 6.0, and for all atomic species we have sought the best discretization parameter $\left(\Omega_{\min }\right.$ and $\left.\Delta \Omega\right)$ values for each $s, p, d$ and $f$ symmetries. All calculations were carried out using a modified version of the ATOMSCF program [17], and for each atomic species the optimization process is repeated until the total energy value is stabilized within ten significant figures. The resulting wave functions are available by request through the e-mail address jorge@cce.ufes.br.

Table I shows the ground and some excited state HF total energies (in hartrees) for the neutral atoms and some cations from $\mathrm{Cs}(\mathrm{Z}=55)$ through $\mathrm{Lu}(\mathrm{Z}=71)$ computed with our AGBSs and with a NHF [5] method. Our basis set sizes are presented in the seventh column. We recall that the AGBSs are generated from the basis sets of Ref. [6]. First, we augmented these basis sets until saturate each symmetry of each atom, and second, using the GCHF [7] method, we reoptimized each AGBS of each atomic species studied here. From Table I, we can see that our total energies, for all atomic specie of interest, are in good agreement with the corresponding NHF [5] values and that our energy errors do not exceed 1.72 mhartree. Here it is important to say that the vector coupling coefficients used in the calculations of the open-shell configurations have been taken from the tabulation by Malli and Olive [18]. These tables show the vector coupling coefficients for the electron configurations $\mathrm{s}, \mathrm{p}^{n}, \mathrm{sp}^{n}, \mathrm{~d}^{n}, \mathrm{sd}^{n}, \mathrm{p}^{m} \mathrm{~d}^{n}, \mathrm{sp}^{m} \mathrm{~d}^{n}$ and $\mathrm{f}^{n}$. The HF total energies of the ground states of the atoms $\mathrm{Ce}$ and $\mathrm{Gd}$ and of some states of the cations $\mathrm{Pr}^{+}, \mathrm{Nd}^{+}$, $\mathrm{Pm}^{+}, \mathrm{Sm}^{+}, \mathrm{Eu}^{+}, \mathrm{Tb}^{+}, \mathrm{Dy}^{+}, \mathrm{Ho}^{+}, \mathrm{Er}^{+}$and $\mathrm{Tm}^{+}$are not calculated here, because the electron configurations of these atomic species have $5 \mathrm{~d}$ and $4 \mathrm{f}$ and $6 \mathrm{~s}$ and $4 \mathrm{f}$ open shells, respectively. The electron configuration of $\mathrm{Lu}^{+}\left({ }^{3} \mathrm{H}\right)$ has $5 \mathrm{~d}$ and $4 \mathrm{f}$ open shells, and thus the wave function for this cation is not generated here.

Table II contains the IPs (in eV) computed by using the Koopmans theorem ( $\varepsilon$ is our orbital energy), the total energy difference $\Delta E=E\left(X^{+}\right)-E(X)[X$ is the atomic symbol and $E\left(X^{+}\right)$and $E(X)$ are our total energies respectively for the cation and the neutral atom presented in Table I], and the experimental values (E $\left.E_{\text {expt. }}\right)[8,9]$.

From Table II we can see that the differences between our IP's calculated through $-\varepsilon$ (see the fourth column) and through $\Delta E$ (see the fifth column) are small for 6 s orbital, indicating that the Koopmans the- orem works for the $6 \mathrm{~s}$ ionization. Besides this, for the $6 \mathrm{~s}$ orbitals, our IPs calculated with these two approaches are very similar to those computed with a NHF method (see the sixth column). For all lanthanide atoms presented in Table II, and from our results for $-\varepsilon$, we can see that the $6 \mathrm{~s}$ orbitals are more diffuse than the corresponding $4 \mathrm{f}$ orbitals, that is, the $6 \mathrm{~s}$ IPs are smaller than the $4 \mathrm{f}$ IPs. For these atoms, it is known that the mean values of $r$ for the 6 s orbitals are larger than those for the $4 \mathrm{f}$ orbitals, that is, the 6 s electrons are far from the nucleus than the $4 \mathrm{f}$ electrons. From La through $\mathrm{Eu}$, both the calculated $-\varepsilon(\sim 4.4-4.6 \mathrm{eV})$ and the experimental $(\sim 5.4-5.8 \mathrm{eV})$ 6s IPs are almost constant. After $\mathrm{Tb}$, the $-\varepsilon$ and experimental $[8,9]$ IPs gradually increase. The experimental IPs are always larger than the $-\varepsilon$ values. To correct this discrepancy, it is necessary to include in the calculations electron correlation effects and relativistic corrections, but this is outside the scope of this work. Here, it is important to say that Jorge et al. have developed the generator coordinate Dirac-Fock (GCDF) [19,20] method for closedshell atoms and a segmented contraction methodology for relativistic Gaussian basis sets [21,22]. From Table II, only $\mathrm{Yb}(\mathrm{Z}=70)$ has closed-shell, thus, for the other atoms presented in this Table, we cannot use the GCDF method to calculate the relativistic IPs.

Besides this, Table II shows that for the lanthanides, the 4 f IPs calculated by us through $-\varepsilon$ and through $\Delta E$ give very different results. The ionization of the electrons in the outermost $6 \mathrm{~s}$ shell causes small reorganization on the whole electron distribution, whereas the inner 4 f electron ionization causes larger reorganization effects because of the appearance of a hole in the inner shell. Thus, for these atoms, it is not appropriated to use the Koopmans theorem to calculate the $4 \mathrm{f}$ electron ionization. For all lanthanide atoms, the $4 \mathrm{f}$ IPs calculated by us $(\Delta E)$ are in good agreement with the corresponding values obtained with a NHF [5] method, and although the calculated $4 \mathrm{f}$ IPs are 1-3 eV greater than the corresponding experimental values [8,9], NHF and our $\Delta E$ calculations describe the experimental trend well.

\section{Conclusions}

In this work we have generated AGBSs for the 45 atomic species presented in Table I with the GCHF [7] method. The largest difference between the total energies calculated by us and by a NHF [5] method is equal to 1.72 mhartree for Lu. Although our $6 \mathrm{~s}$ and $4 \mathrm{f}$ IPs $(-\varepsilon$ and $\Delta E)$ are respectively smaller and larger than the corresponding experimental values [8,9], our cal- 
culations reproduce the experimental trends on the $6 \mathrm{~s}$ and $4 \mathrm{f}$ electron ionizations well. For the $4 \mathrm{f}$ IPs, our $\Delta E$ results are better than those computed with the Koopmans theorem, whereas for 6s IPs the two approaches give similar results.

\section{Acknowledgements}

We acknowledge the financial support of $\mathrm{CNPq}_{\mathrm{q}}$ and Dr. L.T. Peixoto for valuable discussions.

\section{References}

[1] G. Jeske, H. Lauke, H. Mauermam, H. Schumam and T. J. Marks, J. Am. Chem Soc. 107, 8111 (1985).

[2] C.N. Rao and G.W. Raveau, Acc. Chem. Res. 22, 106 (1989).

[3] B. Mann, At. Data Nucl. Dat. Tables 12, 1 (1973).

[4] C. Frose-Fischer, The Hartree-Fock method for Atoms (Wiley, New York, 1977).

[5] H. Tatewaki, O. Matsuoka and T. Koga, Phys. Rev. A 51, 197 91995).

[6] F.E. Jorge, P.R. Librelon, A. Canal Neto, J. Comp. Chem. 19, 858 (1998).

[7] J.R. Mohallem, R. M. Dreizler and M. Trsic, Int. J. Quantum Chem. 20, 45 (1986)

[8] W.C. Martin, L. Hagan, J. Keader and J. Sugar, J. Phys. Chem. Kel. Data 3, 771 (1974).

[9] L. Brewer, J. Opt. Soc. Arn. 61, 1666 (1971).
[10] J.R. Mohallem, Z. Phys. D3, 339 (1986).

[11] F.E. Jorge and R.F. Martins, Chem. Phys. 233, 1 (1998).

[12] E.V.R. de Castro and F.E. Jorge, J. Chem. Phys. 108, 5225 (1998)

[13] F.E. Jorge and M.L. Franco, Chem. Phys. 253, 21 (2000).

[14] F.E. Jorge and E.P. Muniz, Int. J. Quantum Chem. 71, 307 (1999).

[15] J.C. Pinheiro, A.B.F. da Silva and M. Trsic, Int. J. Quantum Chem. 63, 927 (1997).

[16] M. Giordan and R. Custodio, J. Comp. Chem. 18, 1918 (1997).

[17] S.J. Chakravorty, G. Corongiu, J.R. Flores, V. Sonnad, E. Clementi, V. Carravetta and I. Cacelli, in: E. Clementi (Ed), Modern Techniques in Computational Chemistry: MOTECC-89, (ESCOM, Leiden, 1989).

[18] G.L. Malli and J.F. Olive, Technical Report, Part 2, Laboratory of Molecular Structure and Spectra, University of Chicago, 1962- 1963.

[19] F.E. Jorge, A.B.F. da Silva, J. Chem. Phys. 104, 6278 (1996).

[20] F.E. Jorge, A.B.F. da Silva, J. Chem. Phys. 105, 5503 (1996).

[21] F.E. Jorge, A.B.F. da Silva, Chem. Phys. Lett. 289, 469 (1998).

[22] F.E. Jorge, Braz. J. Phys. 29, 557 (1999). 
Table I. Ground and some excited state Hartree-Fock (HF) total energies (in hartree) for the neutral atoms and some cations from Cs through $\mathrm{Lu}$.

\begin{tabular}{|c|c|c|c|c|c|c|c|c|}
\hline \multirow[b]{2}{*}{ Z } & \multirow[b]{2}{*}{ Atom } & \multirow[b]{2}{*}{$6 s$} & \multirow[b]{2}{*}{$5 p$} & \multirow[b]{2}{*}{$5 \mathrm{~d}$} & \multirow[b]{2}{*}{ 4f } & \multicolumn{2}{|c|}{ Present work ${ }^{\mathrm{a}}$} & \multirow{2}{*}{$\mathrm{E}(\mathrm{NHF})^{\mathrm{b}}$} \\
\hline & & & & & & AGBS sizes & $\mathrm{E}$ (AGBSs) & \\
\hline 55 & $\mathrm{Cs}^{+}\left({ }^{3} \mathrm{P}\right)$ & 1 & 5 & 0 & 0 & $31 \mathrm{~s} 23 \mathrm{p} 16 \mathrm{~d}$ & -7553.300775 & -7553.30109 \\
\hline 55 & $\mathrm{Cs}^{+}\left({ }^{1} \mathrm{~S}\right)$ & 0 & 6 & 0 & 0 & $31 \mathrm{ls} 23 \mathrm{p} 16 \mathrm{~d}$ & -7553.809897 & -7553.81032 \\
\hline 55 & $\operatorname{Cs}\left({ }^{2} S\right)$ & 1 & 6 & 0 & 0 & $31 \mathrm{~s} 23 \mathrm{p} 16 \mathrm{~d}$ & -7553.933158 & -7553.93365 \\
\hline 56 & $\mathrm{Ba}^{+}\left({ }^{2} \mathrm{P}\right)$ & 2 & 5 & 0 & 0 & $32 \mathrm{~s} 23 \mathrm{p} 16 \mathrm{~d}$ & -7882.699357 & -7882.69970 \\
\hline 56 & $\mathrm{Ba}^{+}\left({ }^{2} \mathrm{~S}\right)$ & 1 & 6 & 0 & 0 & $32 \mathrm{~s} 23 \mathrm{p} 16 \mathrm{~d}$ & -7883.391878 & -7882.39188 \\
\hline 56 & $\mathrm{Ba}\left({ }^{1} \mathrm{~S}\right)$ & 2 & 6 & 0 & 0 & $32 \mathrm{~s} 23 \mathrm{p} 16 \mathrm{~d}$ & -7883.543396 & -7883.54382 \\
\hline 57 & $\mathrm{La}^{+}\left({ }^{3} \mathrm{~F}\right)$ & 2 & 5 & 1 & 0 & $31 \mathrm{~s} 25 \mathrm{p} 19 \mathrm{~d}$ & -8220.120943 & -8220.12136 \\
\hline 57 & $\mathrm{La}^{+}\left({ }^{3} \mathrm{H}\right)$ & 0 & 6 & 0 & 2 & $31 \mathrm{~s} 25 \mathrm{p} 19 \mathrm{~d} 1 \mathrm{lf}$ & -8220.747938 & -8220.74876 \\
\hline 57 & $\mathrm{La}^{+}\left({ }^{1} \mathrm{~S}\right)$ & 2 & 6 & 0 & 0 & $31 \mathrm{~s} 25 \mathrm{p} 19 \mathrm{~d}$ & -8220.831165 & -8220.83156 \\
\hline 57 & $\mathrm{La}^{+}\left({ }^{3} \mathrm{D}\right)$ & 1 & 6 & 1 & 0 & $31 \mathrm{~s} 25 \mathrm{pl} 9 \mathrm{~d}$ & -8220.908234 & -8220.90861 \\
\hline 57 & $\mathrm{La}\left({ }^{2} \mathrm{~F}\right)^{\mathrm{c}}$ & 2 & 6 & 0 & 1 & $31 \mathrm{~s} 25 \mathrm{p} 19 \mathrm{~d} 11 \mathrm{f}$ & -8221.063346 & -8221.06381 \\
\hline 57 & $\operatorname{La}\left({ }^{2} \mathrm{D}\right)$ & 2 & 6 & 1 & 0 & $31 \mathrm{~s} 25 \mathrm{pl} 9 \mathrm{~d}$ & -8221.066259 & -8221.06670 \\
\hline 58 & $\mathrm{Ce}^{+}\left({ }^{2} \mathrm{D}\right)$ & 2 & 6 & 1 & 0 & $32 \mathrm{~s} 22 \mathrm{pl} 6 \mathrm{~d} 11 \mathrm{f}$ & -8566.330093 & -8566.33091 \\
\hline 58 & $\mathrm{Ce}^{+}\left({ }^{2} \mathrm{~F}\right)$ & 2 & 6 & 0 & 1 & $32 \mathrm{~s} 22 \mathrm{pl} 6 \mathrm{~d} 11 \mathrm{f}$ & -8566.611918 & -8566.61237 \\
\hline 58 & $\mathrm{Ce}\left({ }^{3} \mathrm{H}\right)^{\mathrm{c}}$ & 2 & 6 & 0 & 2 & $32 \mathrm{~s} 22 \mathrm{pl} 6 \mathrm{~d} 1 \mathrm{lf}$ & -8566.918882 & -8566.91957 \\
\hline 59 & $\operatorname{Pr}^{+}\left({ }^{3} \mathrm{H}\right)$ & 2 & 6 & 0 & 2 & $32 \mathrm{~s} 24 \mathrm{pl} 7 \mathrm{~d} 12 \mathrm{f}$ & -8920.819709 & -8920.82088 \\
\hline 59 & $\operatorname{Pr}\left({ }^{4} I\right)$ & 2 & 6 & 0 & 3 & $32 \mathrm{~s} 24 \mathrm{pl} 7 \mathrm{~d} 12 \mathrm{f}$ & -8921.180552 & -8921.18102 \\
\hline 60 & $\mathrm{Nd}^{+}\left({ }^{4} \mathrm{I}\right)$ & 2 & 6 & 0 & 3 & $31 \mathrm{~s} 24 \mathrm{p} 17 \mathrm{~d} 13 \mathrm{f}$ & -9283.519394 & -9283.51980 \\
\hline 60 & $\mathrm{Nd}\left({ }^{5} \mathrm{~T}\right)$ & 2 & 6 & 0 & 4 & $31 \mathrm{~s} 24 \mathrm{p} 17 \mathrm{~d} 13 \mathrm{f}$ & -9283.882339 & -9283.88294 \\
\hline 61 & $\mathrm{Pm}^{+}\left({ }^{5} \mathrm{I}\right)$ & 2 & 6 & 0 & 4 & $31 \mathrm{~s} 25 \mathrm{p} 17 \mathrm{~d} 13 \mathrm{f}$ & -9654.735827 & -9654.73624 \\
\hline 61 & $\operatorname{Pm}\left({ }^{6} \mathrm{H}\right)$ & 2 & 6 & 0 & 5 & $31 \mathrm{~s} 25 \mathrm{p} 17 \mathrm{~d} 13 \mathrm{f}$ & -9655.098345 & -9654.09896 \\
\hline 62 & $\mathrm{Sm}^{+}\left({ }^{6} \mathrm{H}\right)$ & 2 & 6 & 0 & 5 & $31 \mathrm{~s} 23 \mathrm{p} 16 \mathrm{~d} 12 \mathrm{f}$ & -10034.54262 & -10034.5432 \\
\hline 62 & $\operatorname{Sm}\left({ }^{7} F\right)$ & 2 & 6 & 0 & 6 & $31 \mathrm{~s} 23 p l 6 \mathrm{~d} 12 \mathrm{f}$ & -10034.95178 & -10034.9525 \\
\hline 63 & $\mathrm{Eu}^{+}\left({ }^{\top} \mathrm{F}\right)$ & 2 & 6 & 0 & 6 & $32 \mathrm{~s} 23 \mathrm{p} 16 \mathrm{~d} 12 \mathrm{f}$ & -10423.06812 & -10423.0687 \\
\hline 63 & $\operatorname{Eu}\left({ }^{8} \mathrm{~S}\right)$ & 2 & 6 & 0 & 7 & $32 \mathrm{~s} 23 \mathrm{p} 16 \mathrm{~d} 12 \mathrm{f}$ & -10423.54234 & -10423.5430 \\
\hline 64 & $\mathrm{Gd}^{+}\left({ }^{8} \mathrm{~S}\right)$ & 2 & 6 & 0 & 7 & $31 \mathrm{~s} 24 \mathrm{pl} 7 \mathrm{dl} 3 \mathrm{f}$ & -10820.41271 & -10820.4133 \\
\hline 64 & $\mathrm{Gd}\left({ }^{7} \mathrm{~F}\right)^{\mathrm{c}}$ & 2 & 6 & 0 & 8 & $31 \mathrm{~s} 24 \mathrm{p} 17 \mathrm{~d} 13 \mathrm{f}$ & -10820.61651 & -10820.6173 \\
\hline 65 & $\mathrm{~Tb}^{+}\left({ }^{7} \mathrm{~F}\right)$ & 2 & 6 & 0 & 8 & $32 \mathrm{~s} 24 \mathrm{p} 16 \mathrm{~d} 12 \mathrm{f}$ & -11226.29073 & -11226.2914 \\
\hline 65 & $\mathrm{~Tb}\left({ }^{6} \mathrm{H}\right)$ & 2 & 6 & 0 & 9 & $32 \mathrm{~s} 24 \mathrm{p} 16 \mathrm{~d} 12 \mathrm{f}$ & -11226.56769 & -11226.5684 \\
\hline 66 & $\mathrm{Dy}^{+}\left({ }^{6} \mathrm{H}\right)$ & 2 & 6 & 0 & 9 & $31 \mathrm{~s} 22 \mathrm{p} 17 \mathrm{~d} 12 \mathrm{f}$ & -11641.12737 & -11641.1283 \\
\hline 66 & Dy $\left({ }^{5} \mathrm{I}\right)$ & 2 & 6 & 0 & 10 & $31 \mathrm{~s} 22 \mathrm{pl} 7 \mathrm{~d} 12 \mathrm{f}$ & -11641.45139 & -11641.4526 \\
\hline 67 & $\mathrm{Ho}^{+}\left({ }^{5} \mathrm{I}\right)$ & 2 & 6 & 0 & 10 & $31 \mathrm{~s} 22 \mathrm{p} 17 \mathrm{~d} 12 \mathrm{f}$ & -12064.97708 & -12064.9779 \\
\hline 67 & $\mathrm{Ho}\left({ }^{4} \mathrm{I}\right)$ & 2 & 6 & 0 & 11 & $31 \mathrm{~s} 22 \mathrm{pl} 7 \mathrm{~d} 12 \mathrm{f}$ & -12065.28855 & -12065.2898 \\
\hline 68 & $\operatorname{Er}^{+}\left({ }^{4} \mathrm{I}\right)$ & 2 & 6 & 0 & 11 & $32 \mathrm{~s} 23 \mathrm{pl} 6 \mathrm{~d} 12 \mathrm{f}$ & -12497.85416 & -12497.8549 \\
\hline 68 & $\operatorname{Er}\left({ }^{3} \mathrm{H}\right)$ & 2 & 6 & 0 & 12 & $32 \mathrm{~s} 23 \mathrm{pl} 16 \mathrm{~d} 12 \mathrm{f}$ & -12498.15181 & -12497.1528 \\
\hline 69 & $\operatorname{Tm}^{+}\left({ }^{3} \mathrm{H}\right)$ & 2 & 6 & 0 & 12 & $32 \mathrm{~s} 23 \mathrm{pl} 15 \mathrm{~d} 12 \mathrm{f}$ & -12939.83107 & -12939.8320 \\
\hline 69 & $\operatorname{Tm}\left({ }^{2} F\right)$ & 2 & 6 & 0 & 13 & $32 \mathrm{~s} 23 \mathrm{p} 15 \mathrm{~d} 12 \mathrm{f}$ & -12940.17326 & -12940.1744 \\
\hline 70 & $\mathrm{Yb}^{+}\left({ }^{2} \mathrm{P}\right)$ & 2 & 5 & 0 & 14 & $32 \mathrm{~s} 22 \mathrm{p} 16 \mathrm{~d} 12 \mathrm{f}$ & -13390.33045 & -13390.3314 \\
\hline 70 & $\mathrm{Yb}^{+}\left({ }^{2} \mathrm{~F}\right)$ & 2 & 6 & 0 & 13 & $32 \mathrm{~s} 22 \mathrm{p} 16 \mathrm{~d} 12 \mathrm{f}$ & -13391.04533 & -13391.0463 \\
\hline 70 & $\mathrm{Yb}^{+}\left({ }^{2} \mathrm{~S}\right)$ & 1 & 6 & 0 & 14 & $32 \mathrm{~s} 22 \mathrm{pl} 16 \mathrm{~d} 12 \mathrm{f}$ & $-1339] .27930$ & -13391.2803 \\
\hline 70 & $\mathrm{Yb}\left({ }^{1} \mathrm{~S}\right)$ & 2 & 6 & 0 & 14 & $32 \mathrm{~s} 22 \mathrm{p} 16 \mathrm{dl} 2 \mathrm{f}$ & -13391.45499 & -13391.4562 \\
\hline 71 & $\mathrm{Lu}^{+}\left({ }^{3} \mathrm{~F}\right)$ & 2 & 5 & 1 & 14 & $31 \mathrm{~s} 23 \mathrm{p} 18 \mathrm{~d} 12 \mathrm{f}$ & -13850.56605 & -13850.5675 \\
\hline 71 & $\mathrm{Lu}^{+}\left({ }^{3} \mathrm{D}\right)$ & 1 & 6 & 1 & 14 & $31 \mathrm{~s} 23 \mathrm{p} 18 \mathrm{~d} 12 \mathrm{f}$ & -13851.62338 & -13851.6249 \\
\hline 71 & $\mathrm{Lu}^{+}\left({ }^{1} \mathrm{~S}\right)$ & 2 & 6 & 0 & 14 & $31 \mathrm{~s} 23 \mathrm{p} 18 \mathrm{~d} 12 \mathrm{f}$ & -13851.59948 & -13851.6010 \\
\hline 71 & $\mathrm{Lu}\left({ }^{2} \mathrm{D}\right)$ & 2 & 6 & 1 & 14 & $31 \mathrm{~s} 23 \mathrm{p} 18 \mathrm{~d} 12 \mathrm{f}$ & -13851.80628 & -13851.8080 \\
\hline
\end{tabular}

$\sqrt{\mathrm{HF}}$ total energies obtained with our adapted Gaussian basis sets (AGBSs).

"Numerical HF (NHF) total energies obtained from Ref. [5].

${ }^{\mathrm{C}}$ Excited state in the neutral atom. 
Table II. Ionizations potentials (in $\mathrm{eV}$ ) for $6 \mathrm{~s}$ and $4 \mathrm{f}$ electrons.

\begin{tabular}{|c|c|c|c|c|c|c|}
\hline \multirow[b]{2}{*}{ Z } & \multirow[b]{2}{*}{ Atom } & \multirow[b]{2}{*}{ Orbital } & \multicolumn{4}{|c|}{ Ionization Potentials (IPs) } \\
\hline & & & $-\varepsilon^{\mathrm{a}}$ & $\Delta \mathrm{E}^{\mathrm{b}}$ & $\Delta \mathrm{E}^{\mathrm{c}}$ & Expt $^{d}$ \\
\hline 55 & $\operatorname{Cs}\left({ }^{2} \mathrm{~S}\right)$ & $6 s$ & 3.365 & 3.354 & 3.356 & 3.893 \\
\hline 56 & $\mathrm{Ba}\left({ }^{1} \mathrm{~S}\right)$ & $6 s$ & 4.279 & 4.123 & 4.134 & 5.210 \\
\hline 57 & $\mathrm{La}\left({ }^{2} \mathrm{D}\right)$ & $6 s$ & 4.637 & 4.300 & 4.302 & 5.812 \\
\hline \multirow[t]{2}{*}{59} & $\operatorname{Pr}\left({ }^{4} I\right)$ & $6 s$ & 4.461 & - & 4.254 & 5.422 \\
\hline & & $4 f$ & 14.951 & 9.819 & 9.800 & $(7.40)$ \\
\hline \multirow[t]{2}{*}{60} & $\operatorname{Nd}\left({ }^{5} \mathrm{I}\right)$ & $6 s$ & 4.506 & - & 4.288 & 5.489 \\
\hline & & $4 f$ & 16.201 & 9.876 & 9.881 & $(7.66)$ \\
\hline \multirow[t]{2}{*}{61} & $\operatorname{Pm}\left({ }^{6} \mathrm{H}\right)$ & $6 s$ & 4.560 & - & 4.321 & 5.554 \\
\hline & & $4 f$ & 17.107 & 9.865 & 9.870 & $(7.66)$ \\
\hline \multirow[t]{2}{*}{62} & $\operatorname{Sm}\left({ }^{7} \mathrm{~F}\right)$ & $6 s$ & 4.600 & - & 4.607 & 5.631 \\
\hline & & $4 f$ & 18.107 & 11.134 & 11.139 & $(8.61)$ \\
\hline \multirow[t]{2}{*}{63} & $\mathrm{Eu}\left({ }^{8} \mathrm{~S}\right)$ & $6 s$ & 4.651 & - & 4.381 & 5.666 \\
\hline & & $4 f$ & 19.361 & 12.904 & 12.906 & $(9.76)$ \\
\hline \multirow[t]{2}{*}{65} & $\mathrm{~Tb}\left({ }^{6} \mathrm{H}\right)$ & $6 s$ & 4.748 & - & 4.505 & 5.852 \\
\hline & & $4 f$ & 18.906 & 7.536 & 7.537 & $(6.53)$ \\
\hline \multirow[t]{2}{*}{66} & Dy $\left({ }^{5} \mathrm{I}\right)$ & $6 s$ & 4.783 & - & 4.564 & 5.927 \\
\hline & & $4 \mathrm{f}$ & 19.126 & 8.817 & 8.825 & 7.456 \\
\hline \multirow[t]{2}{*}{67} & Ho $\left({ }^{4} \mathrm{I}\right)$ & $6 s$ & 4.833 & - & 4.621 & 6.018 \\
\hline & & $4 f$ & 19.269 & 8.476 & 8.487 & $(7.26)$ \\
\hline \multirow[t]{2}{*}{68} & $\operatorname{Er}\left({ }^{3} \mathrm{H}\right)$ & $6 s$ & 4.874 & - & 4.678 & 6.101 \\
\hline & & $4 \mathrm{f}$ & 19.340 & 8.099 & 8.105 & $(6.97)$ \\
\hline \multirow[t]{2}{*}{69} & $\operatorname{Tm}\left({ }^{2} \mathrm{~F}\right)$ & $6 s$ & 4.918 & - & 4.732 & 6.184 \\
\hline & & $4 \mathrm{f}$ & 19.552 & 9.311 & 9.318 & 7.728 \\
\hline \multirow[t]{2}{*}{70} & $\mathrm{Yb}\left({ }^{1} \mathrm{~S}\right)$ & $6 s$ & 4.958 & 4.781 & 4.785 & 6.254 \\
\hline & & $4 f$ & 19.909 & 11.147 & 11.153 & 8.910 \\
\hline \multirow[t]{2}{*}{71} & $\mathrm{Lu}\left({ }^{2} \mathrm{D}\right)$ & $6 s$ & 5.405 & 4.977 & 4.981 & 6.888 \\
\hline & & $4 \mathrm{f}$ & 29.299 & - & 19.455 & $(16.2)$ \\
\hline
\end{tabular}

a IPs calculated by using Koopmans theorem. $\varepsilon$ is the orbital energy calculated by us.

${ }^{b}$ IPs calculated by using the difference between our cation and neutral atom total energies $\left[\Delta E=E\left(X^{+}\right)-E(X)\right.$,

$\mathrm{X}$ is the atomic symbol] given in Table $\mathrm{I}$.

'IPs obtained with a numerical HF method [5].

${ }^{d}$ Experimental IPs for the $6 s$ and $4 f$ electrons are those given in Refs. [8,9]. The numbers in the parentheses are estimated ones (see Ref. [9]). 